\title{
Pandemic of Cardiovascular Diseases among Post-Menopausal Women; A Brain Storming Update
}

\author{
Alamgir $\mathrm{MA}^{1 *}$, Alamgir $\mathrm{SI}^{2}$ and Khan $\mathrm{MA}^{3}$ \\ ${ }^{1}$ Quaid-E-Azam Medical College, visiting Physician Civil Hospital Bahawlapur, Pakistan \\ ${ }^{2}$ Dr Shahzadi Iram Alamgir ,Quaid-E-Azam medical College Bahawalpur, Pakistan \\ ${ }^{3}$ Muhammad Arbaz Khan, Shahida Islam Medical College Lodhran, Pakistan
}

*Corresponding author: Muhammad Ahmad Alamgir, Assistant professor Medicine QuaidE-Azam Medical College, Bahawalpur, Visiting Physician, Civil Hospital Bahawlapur, Pakistan, Tel: 03027777158; Email: alamgirkhan916@yahoo.com

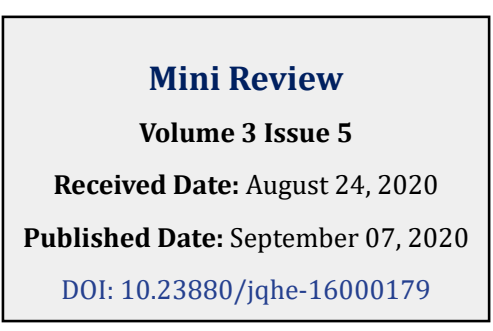

DOI: $10.23880 /$ jqhe-16000179

\section{Abstract}

Among the non-communicable diseases, the cardiovascular events (coronary heart diseases, stroke) are the number one killer of human beings. Among the victims half are women. If we further categorize the women of different age groups, postmenopausal are frequently affected. The present paper aims to review the pathophysiological aspects of this fact and remind the general measures to prevent these events.

Keywords: Coronary Heart Disease; Stroke; Post-Menopausal Women

\section{Introduction}

Recently American heart association presented the statistical documents and estimated that about 8 million deaths occur worldwide due to cardiovascular diseases every year, among them half are women [1]. In general population, cardiovascular diseases like heart attack and stoke represent more deaths than cancer, accidents and lung diseases combined. In United States, there were about 365,914 deaths due to coronary heart diseases in 2017 and women are more likely to suffer [2].

The panorama is more obvious if we consider the fact that 95 percent of cardiovascular (CV) diseases are preventable $[3,4]$.

As cardiovascular event rate is higher in lower and middle income countries, it is most likely due to poverty, lack of education, poor medical facilities and women being ignored in all respects [5]. The present article aims to review the pathological causes and promote preventive measures particularly among women because they are neglected section of society.

\section{Literature Search}

Medical review reveal that central pathological pathway for CV complications is hardening of blood vessels, called as atherosclerosis and it may be related to the sedentary lifestyle, dyslipidaemia, hypertension and diabetes. The cluster of these risk factors is called as metabolic syndrome. The evidence based facts show that there is gender difference among these components of metabolic syndrome and women are more likely to suffer than men [6]. Also they face heart attack much harder than men because their symptoms are much subtle. Randomize control trial concluded that women has less chance to encounter heart attack in the premenopausal period as compared to post-menopausal stage. This is because estrogen has cardio protective role in premenopausal stage and it significantly reduces lipid deposition in vessel walls; this protective role is lost in post postmenopausal stage [7]. Also in early post-menopausal age the process of atherosclerosis is augmented particularly in presence of other risk factors [8]. 
Does hormone replacement therapy will help prevent these catastrophic events among elderly women? WHI was largest land mark trial and its one arm assessed the effect of hormonal replacement therapy in postmenopausal age. The result showed that estrogen therapy did not significantly reduce the prevalence of heart diseases and general preventive measures should be initiated before any drug therapy [9]. Although majority of CV events occur owing due to diabetes and hypertension, but our discussion is related to healthy non diabetic and normotensive postmenopausal women and to remind supportive measures as mentioned below for prevention of risk factors.

\section{Obesity and Overweight}

In 2016, more than 1.9 billion adults were overweight worldwide (more women than men),of these over 650 million were obese [10]. World Health Organization has launched Global action plan on physical activity 20182030: "more active people for a healthier world" and made following recommendation.

- Limit use of refined sugar, junk foods and meat.

- Increase use of vegetables and fruits.

- 30 minutes brisk walk 5 times per week.

\section{Dyslipidaemia}

Lipid abnormalities are characteristically unique among post-menopausal women [11]. Although, raised total and LDL cholesterol has been observed with cardiovascular events but some of the studies revealed no association among them. A systemic review of 30 cohorts concluded that 16 cohorts (representing 92\% of individuals in the review) found an inverse relationship between LDL cholesterol and all-cause mortality [12].

The isolated low HDL-C has been seen as independent risk factors for cardiovascular events particularly among elderly women as higher the HDL-C, beneficial it is [13]. The National Cholesterol Education Panel Adult Treatment Panel suggests that HDL-C levels less than $50 \mathrm{mg} / \mathrm{dL}$ should be considered a risk factor in women [14]. Phan, et al. [15] have comprehensively assessed that LDL-C and total cholesterol were poor while HDL-C and triglycerides were strong predictors of CVD death. The results of a landmark cohort revealed that low HDL-C is risk factor only when associated with high LDL-C levels. Moreover high HDL-C had 20 to 40 percent chance of reduced CV risk [16].

Few evidence based research is available to see correlation of lipid abnormalities among patients of stroke in late reproductive age. Zhang G, et al. [17] randomized 210 women to assess lipid values, scoring of stroke risk and systemic inflammation and reported that post-menopausal were more sufferer from stroke and they favor atorvastatin for these groups. A group of 774 ischemic stroke patient were tested for lipoprotein values in a case control study ( using data from Women's Health Initiative Trial)and reported that triglyceride levels, VLDL particle size and ldl number were significantly associated with stroke among postmenopausal women [18].

But cholesterol is not always "bad". Contrary results were obtained from a cohort of 27,937 women, who were enrolled in a land mark longitudinal Women's Health Study, suffered a hemorrhagic stroke with LDL cholesterol levels of $70 \mathrm{mg} / \mathrm{dL}$ or lower. It was double the rate of women with LDL cholesterol levels between 100 and $130 \mathrm{mg} / \mathrm{dL}$. They also reported that women with the lowest triglyceride levels had higher rates of hemorrhagic stroke $(0.6 \%$ versus $0.4 \%$ in women with higher triglycerides) [19]. It means general measures and life style modification also hold importance.

\section{Life Style Interventions}

Public should be advised to develop a strong will and modify life style because "where there is will, there is way".

International guidelines have recommended that non pharmacological measures should be initiated for prevention of CHD. These include aerobic exercises, diet rich in omega 3 fatty acids and weight reduction. These interventions are helpful to raise HDL-C and also effective in lowering of total cholesterol levels. The Million Hearts Program promoted the community preventive services to prevent one million heart attacks by creating awareness among health care professionals. The key elements are controlling blood pressure and cholesterol level, physical activity, aspirin therapy as appropriate and not to smoke [20].

\section{Conclusion}

Considering the above mentioned review it is apparent that elderly women (post-menopausal) are more likely to be victim of cardiovascular mortality. It is essential for primary care physicians to implement life style modification, heart healthy diet, cessation of smoking with reduced alcohol intake and make this effort possible because $95 \%$ of $\mathrm{CV}$ diseases are preventable.

Success is the result of continuous efforts. "Stone is broken by the last stroke of hammer. It doesn't mean that the first stroke was useless."

\section{Conflict of Interest}

The authors unanimously declare no conflict of interest. 


\section{References}

1. Virani SS, Alonso A, Benjamin EJ, Bittencourt MS, Callaway CW, et al. (2020) Heart Disease and Stroke Statistics-2020 Update: A Report From the American Heart Association. Circulation 141(9): e1-e458.

2. (2020) National Diabetes Statistics Report. Atlanta, GA: Centers for Disease Control and Prevention, US Dept of Health and Human Services.

3. McGill HC, McMahan CA, Gidding SS (2008) Preventing heart disease in the $21^{\text {st }}$ century: implications of the Path biological Determinants of Atherosclerosis in Youth (PDAY) study. Circulation 117(9): 1216-1227.

4. O'Donnell MJ, Chin SL, Rangarajan S, Xavier D, Liu L, et al. (2016) Global and regional effects of potentially modifiable risk factors associated with acute stroke in 32 countries (INTERSTROKE): a case-control study. Lancet 388(10046): 761-775.

5. Anand S, Bradshaw C, Prabhakaran D (2020) Prevention and management of CVD in LMICs: why do ethnicity, culture, and context matter?. BMC Med 18: 7.

6. Alamgir MA, Javid RA, Hameed A, Mustafa I (2015) Gender difference in components of metabolic syndrome among patients of type 2 diabetes. Pak J Med Sci 31(4): 886-890.

7. Karim R, Xu Wenrui, Hodis H (2020) Effect of Estradiol Therapy on Arterial Wall Echo morphology in the Early versus Late Intervention Trial With Estradiol(elite). Circulation 141: AMP09.

8. Samargandy S, Matthews KA, Brooks MM, Barinas Mitchell E, Magnani JW, et al. (2020) Arterial Stiffness Accelerates within 1 Year of the Final Menstrual Period, the SWAN heart study. Arterioscler Thromb Vasc Biol 40(4): 1001-1008.

9. Rossouw JE, Anderson GL, Prentice RL, LaCroix AZ, Kooperberg C, et al. (2013) Risks and benefits of estrogen plus progestin in healthy postmenopausal women: principal results From the Women's Health Initiative randomized controlled trial. JAMA 288(3): 321-333.

10. (2020) Obesity and overweight. World Health
Organization.

11. Alamgir MA, Ahmad I, Raza H (2017) Evaluating the comparative values of lipid profile among premenopausal and postmenopausal women. UJCM 5(1): 1-5.

12. Ravnskov U, Diamond DM, Hama R, Hamazaki T, Hammarskjold B, et al. (2016) Lack of an association or an inverse association between low-density-lipoprotein cholesterol and mortality in the elderly: a systematic review. BMJ Open 6: e010401.

13. Maria LP, Bernabe-Ortiza A, Málaga G, Gilmande RF, Villaorduña A, et al. (2016) Low HDL cholesterol as a cardiovascular risk factor in rural, urban, and rural-urban migrants: PERU MIGRANT cohort study. Atherosclerosis 246: 36-43.

14. Ahmad A (2015) Metabolic syndrome in type 2 diabetes. Comparison of WHO, modified ATP III and IDF criteria. JPak Med Assoc 82(6): 569-574.

15. Phan BAP, Toth PP (2014) Dyslipidemia in women: Etiology and management. International Journal of Women's Health 6: 185-194.

16. Bartlett J, Predazzi IM, Williams SM (2016) Is Isolated Low High-Density Lipoprotein Cholesterol a Cardiovascular Disease Risk Factor? New Insights from the Framingham Offspring Study. Circ Cardiovasc Qual Outcomes (3): 206-212.

17. Zhang J, Wang H, Yang S (2018) Comparison of lipid profiles and inflammation in pre and post-menopausal women with cerebral infarction and the role of atorvastatin in such populations. Lipids Health Dis 17: 20.

18. Berger JS, McGinn AP, Howard BV, Kuller L, Manson JE, et al. (2012) Lipid and lipoprotein biomarkers and the risk of ischemic stroke in postmenopausal women Stroke 43(4): 958-966.

19. Rist PM, Buring JE, Ridker PM, Kase CS, Kurth T, et al. (2019) Lipid levels and the risk of hemorrhagic stroke among women. Neurology 92(19): e2286-e2294.

20. Benjamin, Regina M (2012) The million hearts ${ }^{\mathrm{TM}}$ initiative: progress in preventing heart attacks and strokes. Public health reports 127(6): 558-560. 